\title{
Comprehensible Communication Skill to Excel in Medical
}

\section{Career}

\author{
Subhash C Parija ${ }^{1}$, Padmavathi Shanmuganathan ${ }^{2}$ \\ Annals of SBV (2020): 10.5005/jp-journals-10085-8130
}

The major privilege of healthcare providers is taking care of people during their critical times of illness. The prime responsibility of medical professionals is to ensure the safety of the sick people at their critical times and maintain a good rapport with them when they are under their care and help them to recover fast with their compassionate conversation. Even during this advanced era of information and communication technology, verbal communication is the basic but cardinal requirement for all medical professionals to succeed in their day-to-day medical practice. It is also an essential factor for all the clinicians when they work in a team to maintain a good rapport with their team members and to play the role of an efficient team leader in the system of healthcare.

The huge benefit of better communication skill is the strong development of a trustworthy relationship between the patient and the doctors, resulting in mutual benefits such as better understanding of patient's issues and increase in the work satisfaction for doctors, improvement in patient's compliance to the advice given by the doctors. The chance of conflict between doctors and patients/their attenders will be at a minimum level if the doctor communicates to them with clarity and in a simple, proper, and empathetic way. In case, if a conflict arises, it can be rectified easily in a harmonious way by an effective communicator. ${ }^{1}$ Ineffective communication not only causes harm to the patients but also makes them lose their trust toward doctors which is currently reflected by the escalating pieces of evidence of violence against doctors. ${ }^{2}$ Hence, there is an utmost need to train the undergraduate medical students adequately to improve their art of communication.

Understanding the paramount importance of efficient communication, the current competency-based medical education (CBME) curriculum has included a separate module interlinking the salient trio of the medical profession-attitude, ethics, and communication to stimulate a clear, compassionate, and efficient communication skill among the budding doctors. The module is created to emphasize the importance of doctor-patient communication and how to communicate to the patients properly

${ }^{1}$ Vice Chancellor, Sri Balaji Vidyapeeth, Puducherry, India

${ }^{2}$ Department of Pharmacology, Mahatma Gandhi Medical College and Research Institute, Sri Balaji Vidyapeeth, Puducherry, India

Corresponding Author: Padmavathi Shanmuganathan, Department of Pharmacology, Mahatma Gandhi Medical College and Research Institute, Sri Balaji Vidyapeeth, Puducherry, India, Phone: +91 9842030490, e-mail: padmavathis@mgmcri.ac.in

How to cite this article: Parija SC, Shanmuganathan P. Comprehensible Communication Skill to Excel in Medical Career. Ann SBV 2020;9(2):33. Source of support: Nil

Conflict of interest: None

about their diagnosis, therapy, and prognosis or while dealing with patient's emotional situations or while obtaining informed consent for any interventions. ${ }^{3}$

Active listening is also a salient part of communication and this quality should also be enhanced by all medical professionals which in turn helps them to arrive at a better diagnosis and satisfy the patients who need their utmost attention. ${ }^{4}$

We would like to conclude by saying,

"PractiCe the skills of communication for effective clinical practiSe"

\section{References}

1. Ranjan P, Kumari A, Chakrawarty A. How can doctors improve their communication skills? J Clin Diagn Res 2015;9(3):JE01-JE04. DOI: 10.7860/JCDR/2015/12072.5712.

2. Ghosh K. Violence against doctors: a wake-up call. Indian J of Med Res 2018;148(2):130-133. DOI: 10.4103/ijmr.IJMR_1299_17.

3. National Medical Commission. Competency based undergraduate curriculum - AETCOM module [Internet]. New Delhi. Medical council of India. 2020 December. Available at https://www.nmc.org.in/ wpcontent/uploads/2020/01/AETCOM_book.pdf.

4. Seshadri K. Doctor patient communication. In: Parija SC, Adkoli BV, ed. Effective medical communication: the A, B, C, D, E of it, ch. 5. Springer; 2020. 978-981-15-3408-9.

(c) The Author(s). 2020 Open Access This article is distributed under the terms of the Creative Commons Attribution 4.0 International License (https:// creativecommons.org/licenses/by-nc/4.0/), which permits unrestricted use, distribution, and non-commercial reproduction in any medium, provided you give appropriate credit to the original author(s) and the source, provide a link to the Creative Commons license, and indicate if changes were made. The Creative Commons Public Domain Dedication waiver (http://creativecommons.org/publicdomain/zero/1.0/) applies to the data made available in this article, unless otherwise stated. 